\title{
Distance Education During the 2020 Global Crisis Lockdown
}

\author{
Maria Kicheva ${ }^{1}$, and Boryana Dimitrova ${ }^{1, *}$ \\ ${ }^{1}$ South-West University “Neofit Rilski”, Faculty of Economics, Department of Economics, 2700 \\ Blagoevgrad, Bulgaria
}

\begin{abstract}
.
Research background: Distance education in Bulgarian universities is a relatively new form of human capital training, applied until recently on a limited scale. The global 2020 health and economic crisis, related to the mass lockdown of the in-person educational process throughout the world, has imposed a new challenge to the anti-crisis management of the universities, schools and other educational institutions in Bulgaria: the obligatory application of the distance learning process. For the optimal development of the educational systems in the conditions of similar future crises, it is necessary to have various information about the impact of the crisis on the different groups of educational institutions and especially about the response of the students.

Purpose of the article: This article aims to highlight the identified problems and challenges that distance education is facing and to provide recommendations for its future optimization to individual learners and educators, as well as to the educational institutions themselves and third stakeholders.

Methods: The method of self-administered survey, conducted through Google Forms and the descriptive method, through which the authors of the article share their observations of the educational process, conducted during the lockdown, were used.

Findings \& Value added: Main findings include the pre- and afterlockdown levels of technical armament of the respondents, specifics of the loans taken for its provision, the forms of online training used and the personal assessment of the respondents for their effectiveness, the difficulties encountered during the educational process.
\end{abstract}

Keywords: global crisis; human capital; distance education; loans; efficiency

JEL Classification: $A 22 ; A 23 ; F 69 ; H 12 ; O 15$

* Corresponding author: b_dimi@abv.bg 


\section{Introduction}

In early 2020, the world faced the COVID-19 crisis, which could be classified according to the classification given by Filipova [1] as a geopolitical crisis phenomenon of a global nature and arising as a result of the movement of people and the emergence of diseases threatening humanity.

In some countries, this crisis compounded with others leading to serious challenges to their sustainable development. Brickell et al. [2] argue about the interplay between Cambodia's over-indebtedness, pre-existing malnutrition challenges, and the global public health crisis of COVID-19 being a major threat for social reproduction. Karim, Islam \& Talukder [3] see COVID-19 as an intensifier of numerous other socio-economic crises in Bangladesh such as joblessness, consumption of reserve funds by family members, and shrinking of the country's remittance inflow and suggest the formation of a need-based and skilled workforce as a long-term solution. The last demands an innovative, problem solving thinking to be focused on the issues of human capital's education and training worldwide, but especially in the countries with non-developed economies.

In the sphere of education, the COVID-19 crisis has affected educational institutions to an unprecedented extent - in a number of countries, including Bulgaria, for the first time, there was a complete lockdown of all educational institutions for several months. The need for a lockdown, in connection with COVID-19, is justified at university level mainly by the mandatory responsibility to protect the health and lives of key personnel - the habilitated persons, who in most cases are in the high age category and have some illnesses that make them particularly vulnerable to COVID-19.

Higher education would be blocked, if a large percentage of the staff, on which the system is based, were lost within a few months. This would create further delays and problems with the graduation of students, and then for the business, that expects them to join its ranks as capable and knowledgeable specialists.

This once again confirms the opinion of Delors [4], who, studying the main characteristics of education in the 21 st century, highlights as such its conduct in conditions of uncertainty and dynamism.

The main characteristics of modern life and economies are global interdependence and globalization, the rapid development of processes, and the implementation of constant change. Globalization brings with it both enduring and unknown in the recent past, sudden tensions, problems, and conflicts. This imposes the need for a rapid and adequate adaptation of higher education institutions to external shocks in order to educate the next generation of business' personnel and society's citizens, who are to ensure the sustainable development of systems, rather than their rapid collapse.

In the modern world of regional and global mobility of goods, capital, and people, the qualitative dimensions of population, of human capital, are of key importance for the development of economy and society. Yusof \& Kalirajan [5] argue that human capital is a significant factor influencing changes in economic growth.

In addition, the importance of education of human capital for economic development has been discussed in the scientific literature in various aspects. For example, Alam, Forhad \& Ismail [6] see education as an international product making economic advancement possible. Leighton \& Speer [7] show a connection between the specifics of human capital, in the context of the specialty, and the return on the labor market - the hourly wage of the person and the possibility for one to take a leading position. Rocha et al. [8] examine the effects of higher education expansion on income growth in the context of the growth and heterogeneity of human capital. Campino, Brochado \& Rosa [9] focus on the importance of human capital for the success of the Initial Coin Offerings. Yarrow [10] writes about 
knowledge valuing, in the context of the importance of human capital accounting practices in constructing national economic policies.

Undoubtedly, a key prerequisite in the formation of human capital is the educational process taking place in universities, which is aimed at mastering the knowledge, skills, and competencies by students necessary for their intellectual, physical, and spiritual development and realization. In this sense, any crisis that hinders the normal course of the learning process could have severe consequences both for each learner and for the economy as a whole.

In connection with COVID-19, the universities in Bulgaria moved quickly from the first crisis phase - that of shock, to the second phase of adaptation and control of the situation. Essentially, the crisis management system recommended by Ulmer, Sellnow \& Seeger [11] was realized; it is expressed in constant monitoring of external and internal situations, development of measures to reduce the vulnerability of the organization, increasing the internal flexibility of management, development of anti-crisis plans and immediate implementation of the planned practical measures.

To a large extent, the universities in Bulgaria managed to implement the key state practices described by Anttiroiko [12] in response to COVID-19: focus on human safety, search, and application of creative approaches to the use of spaces (buildings) and digital platforms.

Distance learning has become the norm and has received different appraisals. Among the latest research in this area is the study of Bawack \& Kamdjoug [13]. They confirm that the use of digital information has a significant effect on students. Almaiah, Al-Khasawneh \& Althunibat [14] explore the critical challenges in the use of e-learning systems; one of the groupings discussed is technological challenges, individual challenges, cultural challenges, and course challenges. Evans et al. [15] argue that training university professors to work with a learning system such as Blackboard is effective and leads to greater use of the system's tools.

It would be interesting to follow the opinion of Bulgarian students and educators about the first wave of overall distance learning.

This article aims to highlight the identified problems and challenges that distance learning is facing and to provide recommendations for its future optimization, including to third stakeholders.

\section{Methodology}

An anonymous, self-administered survey instrument was developed to gather information from student respondents about their online educational experience during the spring months of 2020. Respondents were selected from a single university in South-West Bulgaria due to the limitations of the lockdown. The process of conducting the survey had its challenges, the main one being the inability to distribute the questionnaire face-to-face and the need to find a way to administer it online. The authors chose to use the already created for the purposes of the lockdown-online-education messenger groups and the e-mail addresses of the students, they have taught, gathered for the needs of the same educational process.

The first section of the questionnaire gathered demographic information about the age, gender, and permanent residence of the respondents.

The second section gathered information about respondents' current finished level of education and specifics about their ongoing university education.

The third section of the questionnaire focused on their work status, technical armament pre- and after-lockdown, and the need to obtain a loan to acquire the needed computers, 
phones, etc. The specifics of the loans were also inquired, and consequently determined due to this set of questions.

The fourth section of the questionnaire was aimed at gathering information about the 2020 spring lockdown educational process - ways, problems, personal assessment of effectiveness.

An additional question about respondents and their families' fight with the COVID-19 virus was included.

The survey was prepared as a Google-Form questionnaire and the link was distributed through Messenger-groups at the end of the second semester of 2019-2020 academic year to freshmen and other students enrolled at the Faculty of Economics and Law and History Faculty, who have studied micro- and/or macroeconomics and with whom the authors had established a good rapport. At the beginning of 2020-2021 academic year, a second phase of response-collection was conducted through the distribution of the survey link via e-mails towards all bachelor students at the Faculty of Economics and some newly-enrolled students at the Faculty of Pedagogy, who had just studied an entry course in Economics. 118 usable questionnaires were collected.

This article is also based on the descriptive method by which the authors share their observations of the educational process, conducted during the lockdown. The focus is on key issues arising in the course of distance learning, which ask for functional solutions to be sought.

\section{Results}

\subsection{Demographic profile of the respondents}

By the criterion of gender, the respondents are distributed as follows:

- $82 \%(97)$ are women,

- $18 \%(21)$ are men.

Age distribution by groups is:

- $84 \%$ (99) belong to the age group of 18 - to 24 -year-old,

- $8 \%$ (9) to the age group of 25 - to 34 -year-old,

- and the rest $8 \%(10)$ are older than 34 years.

The permanent address of the respondents is in:

- a town: $69 \%(81)$,

- a rural area: $25 \%(30)$,

- the capital: $6 \%(7)$.

\subsection{Educational profile of the respondents}

By the criterion of completed education, the respondents are distributed as follows:

- 92\% (109) have completed only secondary school,

- 8\% (9) have at least one Bachelor's degree.

The respondents are currently enrolled in:

- a Bachelor's programme: 97\% (114),

- a Master's programme: 3\% (4).

They are undertaking:

- a regular (full-time) programme: $81 \%(96)$,

- a part-time programme: $19 \%(22)$.

The ones in Bachelor's programmes are distributed by academic years as follows:

- first-year students: 19\% (22), 
- second-year students: $39 \%$ (44),

- third-year students: $16 \%(18)$,

- fourth-year students: $26 \%$ (30).

The respondents are currently majoring in:

- Tourism: 24\% (28),

- Accounting: 23\% (27),

- Business Management and Entrepreneurship: 14\% (17),

- Finance: $13 \%(15)$,

- Marketing: 7\% (8),

- Economics of Public Sector: 5\% (6),

- Public Administration: 5\% (6),

- Pedagogy of Education in Technology and Entrepreneurship: 4\% (5),

- International Business: 3\% (4),

- Corporate Security: 1\% (1),

- Psychology: 1\% (1).

\subsection{Work status, technical armament, and loan provision of the respondents}

The respondents work status during the 2020 spring lockdown was as follows:

- $60 \%$ (71) didn't work,

- $30 \%$ (35) were employed by a signed labor contract,

- 4\% (5) were self-employed,

$-6 \%$ (7) were engaged in another way.

Before the lockdown the respondents had by their estimation /more than one answer was allowed to be marked/:

- a slower and weaker smartphone: $25 \%$ (29),

- a slower and weaker computer: 18\% (21),

- a slower Internet signal: 14\% (16),

- a faster and more powerful smartphone: $35 \%$ (41),

- a faster and more powerful computer: $39 \%$ (46),

- a faster Internet signal: $46 \%(54)$.

After the lockdown the respondents have by their estimation /more than one answer was allowed to be marked/:

- a slower and weaker smartphone: $13 \%(15)$,

- a slower and weaker computer: $9 \%(11)$,

- a slower Internet signal: 13\% (15),

- a faster and more powerful smartphone: 51\% (60),

- a faster and more powerful computer: 53\% (63),

- a faster Internet signal: 48\% (57).

The change in the speed of the respondents' technical armament was as follows:

- without change: $58 \%$ (68),

- improvement: $30 \%(35)$,

- deterioration: $13 \%(15)$.

Asked, whether they had to borrow money to acquire the needed technical armament for the purposes of distance education during the lockdown, the respondents answered:

- "Yes, I took a loan.": 14\% (17),

- "Yes, my parents took a loan.": 5\% (6),

- "No, I used some savings (mine or my parents').": $8 \%(10)$,

- "No, I had the necessary equipment and internet before.": 72\% (85).

Asked about the source of the money, the 23 respondents who took a loan answered:

- "I borrowed the money from relatives, friends or acquaintances.": 52\% (12), 
- "It was a bank loan.": 43\% (10),

- "It was a quick loan from a non-bank institution.": 4\% (1).

Asked about the type of bank loan, the 10 respondents who borrowed from a bank answered:

- "It was a consumer loan.": $60 \%(6)$,

- "It was a credit card loan.": $30 \%$ (3),

- "It was an overdraft.": $10 \%(1)$.

Asked about the time-frame of the loan, the 23 respondents who took a loan answered:

- up to 1 month: $30 \%(7)$,

- up to 3 months: $9 \%(2)$,

- up to 6 months: $26 \%(6)$,

- up to 1 year: $17 \%(4)$,

- more than 1 year: $17 \%$ (4).

\subsection{0 spring lockdown educational process of the respondents}

During the 2020 spring lockdown the respondents have participated in educational processes conducted via the following forms /more than one answer was allowed/:

- e-mail distribution of study materials: $86 \%$ (101),

- distribution of study materials via the official online platform of the educational institution (e.g. Blackboard): 80\% (94),

- Messenger groups, including voice calls: 64\% (76),

- online sessions during which the lecturer could be heard: $54 \%$ (64),

- Facebook groups: $36 \%(42)$,

- virtual classrooms: 34\% (40),

- written online consultations via chat-applications: $23 \%$ (27),

- distribution of study materials, uploaded on a personal blog/website of the lecturer: $21 \%(25)$,

- Zoom sessions: $20 \%$ (24),

- Google Forms: 7\% (8),

- Microsoft Teams: 4\% (5),

- Microsoft Forms: 3\% (4),

- Google Classroom: 3\% (3),

- Skype sessions: 3\% (3).

Asked which of the aforementioned forms they consider most effective, the respondents answered /more than one answer was allowed to be marked/:

- distribution of study materials via the official online platform of the educational institution (e.g. Blackboard): 66\% (78),

- e-mail distribution of study materials: $64 \%$ (76),

- online sessions during which the lecturer could be heard: $39 \%$ (46),

- Messenger groups, including voice calls: 34\% (40),

- distribution of study materials, uploaded on a personal blog/website of the lecturer: $19 \%(22)$,

- Facebook groups: $16 \%(19)$,

- virtual classrooms: $14 \%(16)$,

- written online consultations via chat-applications: $11 \%$ (13),

- Zoom sessions: 7\% (8),

- Google Forms: 4\% (5),

- Microsoft Teams: 3\% (3),

- Microsoft Forms: 2\% (2),

- Google Classroom: 2\% (2), 
- Skype sessions: $2 \%(2)$.

Asked about the problems they faced during the online education, the respondents answered /more than one answer was allowed to be marked/: (76),

- interruptions, slow internet or no internet connection during online sessions: $64 \%$

- expulsion from online classroom or voice call due to system overload /Blackboard, Messenger group, etc./: 48\% (57),

- inability to attend online due to work obligations: $30 \%(35)$,

- inability to attend online due to lack of sufficient equipment at home and the need for the siblings, students from 1 st to 12 th grade, to conduct online educational sessions: $8 \%$ (10),

- inability to attend online sessions due to health problems: $8 \%$ (9).

Asked about the effectiveness of distance education in comparison to the previous semester, the respondents gave their evaluation as follows:

- "The effectiveness was higher.": $21 \%(25)$,

- "The effectiveness was the same.": 42\% (49),

- "The effectiveness was lower.": $37 \%$ (44).

Asked about whether they would like to be educated distantly in the future, the students responded:

- "Yes": 55\% (65),

- "It's the same for me": $12 \%(14)$,

- "No": 33\% (39).

\subsection{COVID-19 and the respondents}

The respondents were asked an additional question about whether in 2020 they or a member of their family had to undergo medical treatment because of the COVID-19 infection. They answered as follows:

- "Yes": $2 \%(2)$,

- "No": 98\% (116).

\section{Discussions}

The age distribution of the respondents is typical for the student population in Bulgaria. The predominance of women over men corresponds to the observations of the authors, made during non-distant classes. The small percentage of respondents living permanently in the capital is due to the fact that the survey was conducted at a university in a non-capital city.

Bachelors-to-be in full-time education, who have completed only secondary education, predominate among the respondents. They are also prevalent in the general student population, as in recent years, admission in part-time form and in master's programs is limited.

Regarding the employment status of the respondents, the unemployed are expected to predominate, but the percentage of those employed under an employment contract is unexpectedly high (30\%). This is an indication of some financial difficulties in the parental families of the young people, which requires an earlier work-start in order to fill in the income gap. On the other hand, the earlier accumulation of work experience can be interpreted positively, especially when it is in the profession, and will allow for faster career growth.

Before the lockdown, a smaller number of students had faster internet, computers, and smartphones than afterward, which is a testimonial of improvement of their technical armament. There is an improvement of the technical equipment of $30 \%$ of the respondents, 
which shows commitment to the learning process at a high level - the provision of new equipment is done in order to improve the quality of the distance educational process. As expected there is also some deterioration (but only 13\%), which is rather due to the depreciation of the equipment and the delay of the Internet service, related mainly to ISPs' own technical problems and decisions.

The technical re-equipment in the course of the lockdown was realized both with loans $(19 \%)$ and with savings available in the family $(8 \%)$. Only 10 respondents or their parents received a bank loan and 1 - from a non-banking institution. These values are lower than the number of students who have borrowed from relatives, friends, and acquaintances (12). The explanation could be sought in the impossibility of obtaining a bank loan due to borrowers' non-compliance with the bank requirements, as well as in the lack of interest among borrowers due to the high cost of bank loans. However, the existence of savings in the population could be interpreted positively, as well as the psychological readiness for mutual assistance, which has led to the realization of interpersonal loans.

In terms of maturity, the largest percentage of loans is up to 1 month. Only $17 \%$ of the loans will be repaid over a year. This is obviously a good practice - both recipients and lenders have taken into account the risk from the business environment.

During the lockdown, the educational process of the respondents took place using various forms, which can be interpreted positively, as it increases their knowledge and skills to work with different online platforms and would serve them successfully in their future professional realization in case of remote work.

It is gratifying that most of the respondents determine the most effective educational communication through the official online platforms of the educational institution (faculty or school) in which they studied at the time of the lockdown. This is a testament to the rapid adaptation of both students and educators who have managed to supply these platforms with teaching material. In second place is "sharing of study material via e-mail", and in third place are "online sessions in which the educator's voice is heard". The predominance of the first two forms in the students' preferences can be explained by the fact that in case of impossibility to attend a "voice" meeting, the most effective assimilation of the material is directly from the educator's materials and not from possible notes of fellow students. Positive is the use of various forms that allow consultation - asking and answering questions.

Unfortunately, a large percentage of students had technical difficulties, leading to the inability to participate in "voice" meetings, which confirms the need for educators to provide "readable" learning material, and not just "voicing" it.

It is satisfactory for the efforts made by the educators that students give as a whole positive assessment of the effectiveness of distance learning - only $37 \%$ of them determine the effectiveness as "lower".

Another positive feedback is the clearly expressed readiness to study remotely in the future $-55 \%$ of students answer positively to a direct question, and an additional $12 \%$ are also not strongly against.

Fortunately, a minimal percentage of respondents or their family members really had to be treated for coronavirus infection and its consequences. But the very fact that there were such, means that in the event of live classes, the virus could be transmitted to others and the lockdown measures taken by the University have saved inconveniences, pain, costs, and possibly the lives of students and staff.

Some issues of the authors' practice in distance realization of the learning process should be noted, needing to be discussed and solved:

- setting up effective communication channels between educators and students;

- provision of a functional online learning management system, easily accessible from all participants in the learning process; 
- implementation of effective forms for presenting the study material;

- sharing, incl. through online communication between educators, of good practices for working with platforms;

- provision of the necessary, in accordance with the increased needs, server space.

- provision of a backup version of a distance learning platform, which is to be used in the event of a sudden collapse of the first;

- technical prophylaxis of the personal hardware and software in order to carry out an effective distant educational process.

\section{Conclusions}

In the global crisis situation caused by COVID-19, the first attempt of Bulgarian universities to conduct comprehensive distance learning can be defined as successful, especially in teaching economic subjects that do not require real "live" practice. The available platforms, the general competence of staff and students, and the creative search for opportunities and implementation of solutions led to a predominantly effective transfer of knowledge. It remains for universities to keep improving the knowledge and skills of their human capital and to continuously upgrade their technical armament and security in relation to distance learning and work processes in order to successfully take their place in the highly competitive educational market.

As a result of the global lockdown, societies are moving towards maximum digitalization of their business activities. This requires companies, trading in new and used computer and telephone equipment, as well as Internet providers, to be prepared with products at different price categories in order to respond quickly to the needs of learners and trainers, companies, and customers.

This article presented some of the current challenges and effective solutions regarding distance learning at the university level; recommendations for its future optimization were also made, incl. to third interested parties.

This paper is an outcome of the project: RP-B4/20 Research of risk management in the conditions of digital and globalized economy.

\section{References}

1. Filipova, M. (2009). Enterprise management in crisis situations. Blagoevgrad: Univercity Publishing House „Neofit Rilski“.

2. Brickell, K., Picchioni, F., Natarajan, N., Guermond, V., Parsons, L., Zanello, G. Bateman, M. (2020). Compounding crises of social reproduction: Microfinance, overindebtedness and the COVID-19 pandemic. World Development, 136, 105087.

3. Karim, M.R., Islam, M.T., Talukder, B. (2020). COVID-19's impacts on migrant workers from Bangladesh: In search of policy intervention. World Development, 136, 105123.

4. Delors, J. (1996). Learning: the treasure within: report to UNESCO of the International Commission on Education for the Twenty-first Century. Paris: UNESCO Publishing.

5. Yusof, Y., Kalirajan, K. (2020). Variations in economic growth across states in Malaysia: an exploratory analysis. Journal of Economic Studies, forthcoming article.

6. Alam, G. M., Forhad, A. R., Ismail, I. A., (2020). Can education as an 'international commodity' be the backbone or cane of a nation in the era of fourth industrial 
revolution? - A comparative study. Technological Forecasting and Social Change, $159,120184$.

7. Leighton, M., Speer, J. D. (2020). Labor market returns to college major specificity. European Economic Review, 128, 103489.

8. Rocha, L. A., Silva, N. G. A., de Almeida, C. A. S., de Oliveira, D. M., Fernandes, K. C. (2020). Growth and heterogeneity of human capital: effects of the expansion of higher education on the increase in income in Brazilian municipalities. Cepal Review, 131, 95-118.

9. Campino, J., Brochado, A., Rosa, A. (2020). Human capital's importance in initial coin offerings' (ICOs) success. Economics Bulletin, 40(3), 2016-2022.

10. Yarrow, D. (2020). Valuing knowledge: The political economy of human capital accounting. Review of International Political Economy, forthcoming article.

11. Ulmer, S., Sellnow, T., Seeger, M. (2007). Effective crisis communication: moving from crisis to opportunity. Thousand Oaks: SAGE Publications.

12. Anttiroiko, A. (2021). Successful government responses to the pandemic: contextualizing national and urban responses to the COVID-19 outbreak in East and West. International Journal of E-Planning Research (IJEPR), 10(2), 1-17.

13. Bawack, R. E., Kamdjoug, J. R. K. (2020). The role of digital information use on student performance and collaboration in marginal universities. International Journal of Information Management, 54, 102179.

14. Almaiah, M. A., Al-Khasawneh, A., Althunibat, A. (2020). Exploring the critical challenges and factors influencing the e-learning system usage during COVID-19 pandemic. Education and information technologies, 1-20.

15. Evans, J. C., Yip, H., Chan, K., Armatas C., Tse, A. (2020). Blended learning in higher education: professional development in a Hong Kong university. Higher Education Research \& Development, 39(4), 643-656. 